\title{
CRYPTOCURRENCY AND THE STATE: AN UNHOLY ALLIANCE
}

\author{
LEE REINERS*
}

\section{INTRODUCTION}

Despite the convenient claim made in traditional economic textbooks that money arose naturally in barter-based societies as a means of satisfying the "double coincidence of wants," money has always been a creature of the state. Historically, governments have demonstrated their power by monopolizing the creation of money, which in turn further legitimized the government's authority. In this sense, money and the state are selfreinforcing, and states rarely tolerate attempts to subvert their control over money's creation and distribution, let alone attempts to redefine what money is. This is why the emergence of cryptocurrency is so fascinating, as its growing prominence seemingly defies what centuries of anthropological records have led us to believe about the relation between money and the state. Cryptocurrency's staying power also necessitates a reassessment of the role of government in the twenty-first century. If cryptocurrency is a fundamental challenge to sovereignty, why haven't more countries cracked down on its usage or banned it outright? Why have some countries done the opposite of what history has taught us to expect, and embraced the use of cryptocurrency?

This Article contextualizes the rise of cryptocurrency within the historical relationship between money and the state. It begins by asking two simple, yet critical, questions: What is money, and where did it come from? Armed with the answers, this Article proceeds by taking a fresh look at cryptocurrency through the lens of the credit theory of money. It finds that cryptocurrency, by using new technologies and incentive-based design, attempts to overcome the previous geographic limitations that hindered broad adoption of private currencies. ${ }^{1}$ Even with these innovations, cryptocurrency appeared unlikely to challenge the supremacy of sovereign money until Facebook announced the Libra project. Policymakers around the world instantly recognized the threat and opportunity Libra posed, given Facebook's scale. Facebook may not be a sovereign entity, but its power rivals that of most countries. Libra compelled a flurry of new proposals in the United States to address the fragmented nature of cryptocurrency regulation. In choosing their next steps, Congress and regulators must be

* Lecturing Fellow and Executive Director of the Global Financial Markets Center at Duke University School of Law. The author would like to thank Ryan Clements and Lawrence Baxter for helpful comments and edits, and Sherry Zhang for research support.

1 This article uses the term cryptocurrency, which technically refers to a digital or virtual currency that is secured by cryptography. Bitcoin was the first cryptocurrency, thereby ushering the term into the mainstream lexicon. However, for purposes of this Article, the terms cryptocurrency, virtual currency, and digital currency are interchangeable, provided they refer to a non-state-backed currency issued via the internet. 
careful to ensure that regulatory clarity does not come at the expense of sovereign authority.

\section{THE HISTORY OF MONEY}

\section{A. DEFINING MONEY}

Money is typically defined by the functions it performs: unit of account, store of value, and medium of exchange. But rarely is money described in terms of what it is.

At its core, money is a unit of measure, like an inch or an ounce. But, whereas we can conceptualize the distance an inch represents and the weight of an ounce, what does money measure ${ }^{2}$ Money, in effect, measures debt, or who owes what to whom. Returning to the traditional economics origin story, money arose to solve the hassle of barter. ${ }^{3}$ If one villager needed a pig for a feast, he may be able to obtain it from another villager for four clay pots, or a different villager for ten pairs of shoes. Constantly making mental calculations to determine the best value for a pig, or whatever else you are trying to acquire, is time consuming; thus, money is "born." The problem with this story is that it is simply not true. ${ }^{4}$ In reality, these villagers know one another; rather than exchange ten pairs of shoes for one pig, the villager who provides the pig simply takes note of the contribution and that his fellow villager owes him something of comparable value. This is the same thing as credit, and the archaeological record reveals that credit systems of this sort "preceded the invention of coinage by thousands of years."

The credit theory of money contends that money, like a dollar, is simply an abstract unit of measurement, and that you "can no more touch a dollar or a deutschmark than you can touch an hour or a cubic centimeter." 6 Thus, money can be thought of as way to measure IOUs, or debt, and currency is simply what is used to clear credit accounts. ${ }^{7}$ For our villagers, currency is not valuable in-and-of itself, rather, it is valuable because the recipient can exchange it to receive something of equivalent value to one pig.

In some cases, currency rarely changed hands, meaning credit accounts were cleared only sporadically. Take the Pacific Island of Yap, whose residents, until the early twentieth century, relied on coinage called fei that consisted of "large, solid, thick, stone wheels, ranging in diameter from a foot to twelve feet, having in the centre a hole varying in size with the diameter of the stone, wherein a pole may be inserted sufficiently large and

${ }^{2}$ Christine A. Desan, The Constitutional Approach to Money: Monetary Design and the Production of the Modern World, in MONEY TALKS: EXPLAINING HOW MONEY REALLY WORKS 109, 112 (Nina Bandelj, Frederick F. Wherry \& Viviana A. Zelizer eds., 2017) [hereinafter Desan, Constitutional Approach].

${ }^{3}$ To be fair to economists, even Aristotle subscribed to the belief that money arose to solve the problem of barter. See ARISTOTLE, POLITICS 16 (Benjamin Jowett trans., Oxford: Clarendon Press, 1905) (350 B.C.E.).

${ }^{4}$ Anthropologist Caroline Humphrey stated, "No example of a barter economy, pure and simple, has ever been described, let alone the emergence from it of money; all available ethnography suggests that there has never been such a thing." See Caroline Humphrey, Barter and Economic Disintegration, 20 MAN 48-72 (1985).

\footnotetext{
${ }^{5}$ DAVID Graeber, DEBT: The First 5,000 Years 38 (2011).

6 Id. at 46.

${ }^{7}$ See Felix Martin, Money: The Unaut horised Biography 16 (Vintage Books 2015) (2013).
} 
strong to bear the weight and facilitate transportation."8 Rather than transact with the cumbersome fei, islanders would simply offset debts against one another, "with any outstanding balance carried forward in expectation of some future exchange." 9 Only occasionally, when outstanding balances between two islanders became quite large, would fei change hands.

\section{B. STATE THEORY OF MONEY}

If currency is simply anything that others will accept as payment, how do you trust that a specific currency will be accepted? Enter the state, who has always had a vested interest in standardizing units of measurements within its borders. ${ }^{10}$

In his book The State Theory of Money, published in 1905, historian G.F. Knapp postulated that "the money of a State is not what is of compulsory general acceptance, but what is accepted at the public pay offices; and that the standard is not chosen for any properties of the metals, but for the deliberate purpose of influencing exchanges with the commercially important neighbouring States." 11 This view, that money derives its value from its status as legal tender, became known as Chartalism, and it remains outside the mainstream of economic theory despite a grip on historical truth that tightens with each passing decade. ${ }^{12}$ The late anthropologist David Graeber offers a simple hypothetical to explain the Chartalist moneycreation story:

Say a king wishes to support a standing army of fifty thousand men. Under ancient or medieval conditions, feeding such a force was an enormous problem. Such a force would likely consume anything edible within ten miles of their camp in as many days; unless they were on the march, one would need to employ almost as many men and animals just to locate, acquire, and transport the necessary provisions. On the other hand, if one simply hands out coins to the soldiers and then demands that every family in the kingdom was obliged to pay one of those coins back to you, one would, in one blow, turn one's entire national economy into a vast machine for the provisioning of soldiers, since now every family, in order to get their hands on the coins, must find some way to contribute to the general effort to provide soldiers with things they want. Markets are brought into existence as a side effect. ${ }^{13}$

\footnotetext{
${ }^{8}$ William Henry Furness, III, The ISLAND of Stone MONEy: UAP of ThE Carolines 93 (1910).

${ }^{9}$ MARTIN, supra note 7 , at 8 .

${ }^{10}$ GRAEBER, supra note 5 , at 47.

11 GEORG FrIEDRICH KNAPP, THE STATE THEORY OF MONEY vii (H.M. Lucas \& J. Bonar trans., Macmillan \& Co. 4th ed. abr. 1924).

${ }^{12}$ While Chartalism remains on the fringes of economic theory, arguably the most influential economist of all time, John Meynard Keynes, came to accept the Chartalist position, arguing in his "Treatise on Money" that "[t]o-day all civilized money is, beyond the possibility of dispute, chartalist." See JOHN MAYNARD KEYNES, A TREATISE ON MONEY 4-5 (1930).

${ }^{13}$ GraEBER, supra note 5, at 49-50.
} 
By the mere act of government spending and taxation, money is created. According to the Chartalist view, the content of money matters little. Graeber's example refers to "coins," but he could have just as easily said bills, cowry shells, or the generic term "token," all of which are simply units of account. ${ }^{14}$ These tokens act like receipts, and the "receipts hold value because officials agree to take those tokens in lieu of further work when communal contributions are due."15 Because tokens issued are equal to tokens redeemed, the citizenry view the system as credible and imbue the token with "substantive and uniform value."16 But, if the token can be easily manipulated or counterfeited, equivalency breaks down and the system is no longer credible. This is why coins made of precious metal emerged as the quintessential currency in ancient times and have retained such a tight hold over imaginations and theories of money ever since. Precious metals are scarce, durable, and difficult to imitate. The state also benefits from controlling the mining of these metals, thereby granting the state an exclusive monopoly over money creation. ${ }^{17}$

Because all citizens must pay taxes and thus share a common creditor, government-issued tokens can freely circulate as currency within the community. People are willing to accept these tokens as payment, because they know that they can use the tokens to pay their obligations to the state. ${ }^{18}$ Historically, tokens also came with collateral-their metal content-which served to further support their acceptance and legitimate the state. ${ }^{19}$

The problem with a token system based on equivalence-meaning tokens issued equals tokens redeemed-is that it leads to currency shortages whenever taxes are due or state spending declines. To alleviate this issue, monetary systems evolved to allow people to "expand the money supply by their own action for their own use."20 This was done through the process of "free minting," whereby individuals seeking additional units of currency could bring bullion to the government mint and receive coin in return, for a fee. Free minting advantaged the government by imposing the costs of money creation on the citizenry and stabilizing prices. Should prices decline,

${ }^{14}$ Karl Polanyi considered money, along with land and labor, to be a "fictious commodity," because they were not originally produced to be sold on a market. This fiction, by necessity, is maintained by the state. Therefore money, according to Polanyi, "is merely a token of purchasing power which, as a rule, is not produced at all, but comes into being through the mechanism of banking or state finance." See KARL PolANYI, THE GREAT TRANSFORMATION 75-76 (Beacon Press 2d ed. 2001) (1944).

${ }^{15}$ Desan, Constitutional Approach, supra note 2, at 113.

16 Desan, Constitutional Approach, supra note 2, at 116.

17 Friedrich Hayek argued that the government's monopoly over the money supply, even when anchored to gold, leads to inflation and destabilizing business cycles. He believed that money would be better supplied through competition by private issuers: "I have now no doubt whatever that private enterprise, if it had not been prevented by government, could and would long ago have provided the public with a choice of currencies, and those that prevailed in the competition would have been essentially stable in value and would have prevented both excessive stimulation of investment and the consequent periods of contraction." As this article highlights, the public now has the choice between thousands of new cryptocurrencies, none of which have come close to challenging the prominence of state money, let alone demonstrate the stable value Hayek believed such competition would bring about. See FRIEDRICH HAYEK, DENATIONALISATION OF MONEY: THE ARGUMENT REFINED 14 (Inst. of Econ. Affairs 3d ed. 1990) (1976).

18 Id. at 7.

19 See, e.g., Money Talks: EXPlaining How Money Really Works 109, 112 (Nina Bandelj, Frederick F. Wherry \& Viviana A. Zelizer eds., 2017) 12 ("Should a regime fail and, with it, the counted quality of money, people would still hold its commodity value if not its monetary value.").

${ }_{20}$ Christine A. Desan, Creation Stories: Myths About the Origins of Money 50 (Harv. L. Sch. Pub. L. Working Paper, Paper No. 13-20, 2013), https://ssm.com/abstract=2252074. 
individuals could bring bullion to the mint in exchange for coin, thereby increasing the money supply and prices. Individuals benefited through the ability to obtain currency on-demand, which typically was worth more than its bullion content-known as the cash premium-due to its function as a medium of exchange. ${ }^{21}$

Even with free minting, there are limits to how far the money supply can grow, notably, the available supply of bullion. As European colonialism emerged in the fifteenth century and mercantilist policies came shortly thereafter, severe currency shortages became the norm in the colonies. In a bold stroke, American colonial governments solved this shortage, while at the same time claiming political authority for themselves, by issuing bills of credit to pay soldiers' wages. ${ }^{22}$ Because colonial legislatures had the authority to tax and spend, they issued bills of credit (also known as notes) denominated in standard English units (for example, shillings). These notes could be used by soldiers or any bearer to pay provincial taxes. But even this method did not fully satisfy the public's need for currency, as the volume of notes put into circulation was determined by the sporadic spending needs of provincial governments, which at the time primarily related to defense. Thus, a new system was created whereby provincial authorities could "offer[] bills of credit to inhabitants who might like to borrow them."23 Provincial governments would accept land as security for these loans and require principal and interest be repaid in the same bills. This system divorced money creation from the state's fiscal needs and allowed money to be more evenly distributed within the colonies due to the abundance of land and the colonial emphasis on landownership.

Recognizing the threat that colonial bills of credit posed to their ability to control their territories, the British Parliament passed the Currency Act of 1764 , which forbade the colonies from "issuing any paper bills, or bills of credit of any kind or denomination whatsoever." $" 24$ The Currency Act further hardened colonial resistance to British rule and reinforced the importance of controlling the supply of currency. The latter lesson is reflected in Article 1 of the U.S. Constitution, which provides Congress the exclusive authority " $[\mathrm{t}] \mathrm{o}$ coin $[\mathrm{m}]$ oney, regulate the [v]alue thereof, and of foreign [c]oin, and fix the [s]tandard of [w] eights and [m] easure."'25

The linkage between monetary authority and political authority was understood long before pesky American colonialists provoked their sovereign by issuing bills of credit. The Guanzi, an ancient Chinese political and philosophical text from the seventh century BCE., is the oldest piece of writing to acknowledge money as a tool of the sovereign, ${ }^{26}$ stating, "[T]he prescient ruler grasps the reins of the common currency in order to bridle the Sovereigns of Destiny.".27

\footnotetext{
${ }^{21}$ See Desan, Constitutional Approach, supra note 2, at 113.

22 See Desan, Constitutional Approach, supra note 2, at 117-18.

${ }_{23}$ Desan, Constitutional Approach, supra note 2, at 120.

${ }_{24}$ Currency Act of 1764,4 Geo. 3, c. 34 (Eng.).

${ }^{25}$ U.S. CONST. art. $1, \S 8$, cl. 5.

${ }^{26}$ MARTIN, supra note 7, at 75

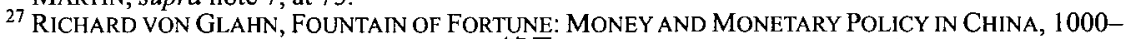
170030 (U.C. Press 1996) (quoting the Guanzi (管子), an ancient Chinese philosophical text).
} 


\section{MONETARY INNOVATION}

Historically, most expressions of political authority took the form of violence or war. Therefore, monetary innovation tends to be concentrated around periods of armed conflict. Such is the case of the Bank of England, which received its Royal Charter in 1694. While the Charter indicated that the Bank was established to "promote the public[] Good and Benefit of our People," 28 the real motivation for the Bank was to help fund the expensive war effort against France. The Bank was originally owned by a group of private investors who lent 1.2 million pounds in the form of Bank of England notes-which represented promises-to-pay specie issued by the Bank-to the King and Parliament in exchange for a royal monopoly on the issuance of banknotes. ${ }^{29}$ Once the government started spending these notes and accepting them as payment for tax obligations, they circulated throughout the British economy and " $[\mathrm{h}]$ olders could use banknotes to pay each other; anyone holding a note could take it to the $[\mathrm{B}]$ ank for face value.", $3^{\circ}$ Furthermore, the government allowed the Bank of England and other commercial banks to "lend to private individuals and businesses by issuing notes that promised-to-pay the official unit of account on demand." ${ }^{\prime \prime}$ By issuing notes in excess of the specie they held, these banks ushered in the era of fractional reserve banking and private money creation. This system, while slightly altered over the past three hundred years, remains the foundation of modern central banking and monetary policy implementation. It implicates the banking sector as an extension of the sovereign through its role in creating and circulating sovereign money. ${ }^{32}$

Alexander Hamilton and the Federalist Party aside, the United States was slow to embrace the English public-private partnership model of money creation, owing in no small part to Americans' historical distrust of centralized authority. Although the first and second Bank of the United States did issue dollar-denominated banknotes that were widely accepted at par, these notes were not sovereign-issued liabilities. ${ }^{33}$ With the failure to recharter the second Bank of the United States in 1834, the free banking era began. During this period, currency principally consisted of state-chartered banknotes that were "redeemable in specie and backed by government bonds (typically issued by the state where the bank was located). ${ }^{.34}$ With thousands

\footnotetext{
${ }^{28}$ Bank of England Act of 1694, 5 \& 6 W. \& M. c. 20.

29 GRAEBER, supra note 5, at 339-40; Desan, Constitutional Approach, supra note 2, at 122; Our History, BANK OF ENG. (Jan. 22, 2021), https://www.bankofengland.co.uk/about/history.

${ }^{30}$ Desan, Constitutional Approach, supra note 2, at 122.

${ }^{31}$ Desan, Constitutional Approach, supra note 2, at 124.

32 Professors Saule Omarova and Bob Hockett argue that, within this framework, "the sovereign public, as franchisor, effectively licenses private financial institutions, as franchisees, to dispense a vital and indefinitely extensible public resource: the sovereign's full faith and credit." See Robert C. Hockett \& Saule T. Omarova, The Finance Franchise, 102 CORNELL L. REV. 1143, 1147, 1210-11 (2017).

${ }^{33}$ Although chartered by the government, the first and second bank were commercial banks with private shareholders, with the federal government as a shareholder in both banks. The banks' notes were backed by substantial gold reserves. See Andrew T. Hill, The First Bank of the United States, FED. RSRV. HIST. (Dec. 4, 2015), https://www.federalreservehistory.org/essays/first bank of the us; see also Andrew T. Hill, The Second Bank of the United States, FED. RSRV. HIST. (Dec. 5, 2015), https://www.federalreservehistory.org/essays/second bank of the us.

${ }^{34}$ Hugh Rockoff, Lessons From the American Experience With Free Banking 5 (Nat'l Burcau of Econ. Rsch., Working Paper No. h0009, 1989), https://ssm.com/abstract=253991. These bonds were deposited with a state official who was empowered to sell the bonds and redeem all the notes of a bank if one note was protested for non-payment.
} 
of different banknotes freely circulating, conducting commerce was quite challenging. Although they were denominated in dollars, these notes all traded at different par values based upon the perceived soundness of the issuing bank, which was influenced in part by how far the issuing bank was located from the merchant accepting the note. This meant that shopkeepers and tradesmen "had to maintain regularly updated discount schedules behind their counters, instructing clerks how much to discount different banks' notes in determining 'how much' (of what) to charge buyers for goods or for services." $" 35$

Once again, the onset of war refocused attention on the link between money and governance. The Civil War necessitated a uniform national currency that the federal government could spend anywhere to fund the war effort. ${ }^{36}$ In response, Congress passed the Legal Tender Act in 1862, which allowed the government to print paper notes, known as "greenbacks," that were not backed by a similar amount of gold and silver but were acceptable for all debts, public and private. ${ }^{37}$ This was followed by the National Currency Act of 1863 and the National Banking Act of 1864, which established a system of federally-chartered "National Banks," a uniform national currency, and an active secondary market for Treasury securities. When the government imposed a ten percent tax on the issuance of all state banknotes in 1865 , they ceased being issued. ${ }^{38}$

Through fits and starts, the United States came to recognize the importance of money to state power. ${ }^{39}$ As President Lincoln was purported to have said, "Money is the creature of law, and the creation of the original issue of money should be maintained as an exclusive monopoly of the National Government. . . The privilege of creating and issuing money is not only the supreme prerogative of the Government, it is the Government's greatest opportunity. $" 40$

${ }^{35}$ Robert C. Hockett, Money's Past is Fintech's Future: Wildcat Crypto, the Digital Dollar, and Citizen Central Banking, 2 STAN. J. BLOCKCHAIN L. \& POL'Y 221, 225 (2019), https://stanfordjblp.pubpub.org/pub/wildcat-crypto-fintech-future/release/1.

36 Id.
${ }^{37}$ Fed. Rskv. Bank of Phila., The State and National Banking Eras: A Chapter IN the HISTORY OF CENTRAL BANKING 7 (2016), https://fraser.stlouisfed.org/files/docs/publications/education/ frbphi-chapters-state-national-banking-eras.pdf.

${ }^{38} \mathrm{Id}$. at 12 .

${ }^{39}$ Note that the National Bank Acts did not eliminate all non-federal government-backed currencies. During the Great Depression, hundreds of local currencies, or "scrip," were circulated, the most popular of which were tax anticipation scrip issued by municipal governments. Municipalities sold tax anticipation scrip to fund ongoing obligations while awaiting the periodic influx of tax payments. This scrip could then be used to pay municipal tax obligations, thereby adhering to the Chartalist origin of money. Given that economic crisis gave rise to the issuance of this scrip, once the crisis subsided, municipal finances recovered, and tax anticipation scrip was no longer necessary. For a detailed explanation of tax anticipation scrip during the Great Depression, see generally Loren Gatch, Tax Anticipation Scrip as a Form of Local Currency in the USA During the 1930s, 16 INT'L J. CMTY. CURRENCY RSCH. 22 (2012), https://ijccr.files.wordpress.com/2012/07/ijecr-2012-gatch.pdf.

40112 Cong. Rec. 14,996 (1966). The authenticity of this quote is of some debate and suspicion. It first appears in the book ALADDIN'S LAMP: THE WEALTH OF THE AMERICAN PEOPLE published in 1945. The book's author, Gorham Bert Munson, notes that the quote is a summary of Lincoln's financial views made by the Hon. G. G. McGeer of the Canadian Parliament and has been checked for fidelity to Lincoln's writings by the Library of Congress Legislative Reference Service, which reported that "the statements. . are not in Lincoln's own words, but they represent his monetary views as recorded in his writings." GORHAM BERT MUNSON, AlADDIN'S LAMP: THE WEALTH OF THE AMERICAN PEOPLE 346 (Creative Age Press 1945). All other references, even in the Congressional Record, print it as a direct quote. While these 


\section{CRYPTOCURRENCY AS MONEY}

\section{A. BITCOIN OVERCOMES GEOGRAPHIC LIMITATIONS OF PRIVATE MONEY}

Many scholars and market commentators have assessed how well cryptocurrency fulfills the functions of money, with the consensus being that cryptocurrency is a poor medium of exchange and unit of account-owing principally to its volatility ${ }^{41}$ - and that the only demonstrable use thus far is as a store of value (in reality, a means of speculation). ${ }^{42}$ Others have taken a more expansive view and argued that cryptocurrency represents a new form of shadow money, ${ }^{43}$ akin to commercial paper, repurchase agreements, and money market funds - assets that are considered "safe, short-term, and liquid, and as such, 'cash equivalents' similar to insured deposits in the commercial banking system." 44 However, few have examined cryptocurrency according to the credit theory of money.

In some respects, cryptocurrencies, particularly those running on a public blockchain, ${ }^{45}$ resemble ancient Mesopotamian cuneiform banking records, which were maintained by temple bureaucrats to calculate debts in silver shekels (the monetary unit at the time) ${ }^{46}$ But rather than have a central repository, cryptocurrencies typically rely on distributed ledger technology to maintain the entire transaction history. In the case of Bitcoin - the first and most highly valued cryptocurrency - a network of computers (nodes) all maintain the exact same copy of the ledger that includes the history of every transaction that has ever occurred. Relying on sophisticated cryptography and ingenious incentive-based design, Bitcoin and other cryptocurrencies

may not be Lincoln's exact words, his vigorous support of the National Bank Acts implies that he no doubt held such sentiments to be true. See id.; see also 112 Cong. Rec. 14,996 (1966).

${ }_{41}$ In bitcoin's case, much of this volatility can be attributed to its fixed supply. There will only ever be a maximum of twenty-one million bitcoin in circulation at any time.

${ }_{42}$ See David Milliken, BoE's Carney Says Bitcoin Has 'Pretty Much Failed' as Currency, ReuTERS (Feb. 19, 2018), https://www.reuters.com/article/us-britain-boe-carney-currencies/boes-camey-saysbitcoin-has-pretty-much-failed-as-currency-idUSKCNIG320Z; see also David Yermack, Is Bitcoin $a$ Real Currency? An Economic Appraisal, in THE HANDBOOK OF DigiTAL CURRENCY: BITCOIN, INNOVATION, FINANCIAL INSTRUMENTS, AND BIG DATA 31, 32 (David Lee Kuo Chuen ed., 2015) ("I argue that bitcoin does not behave much like a currency according to the criteria widely used by economists. Instead bitcoin resembles a speculative investment similar to the Internet stocks of the late 1990s."); Aswath Damodaran, The Crypto Currency Debate: Future of Money or Speculative Hype?, MUSINGS ON MKTS. (Aug. 1, 2017, 10:05 PM), http://aswathdamodaran.blogspot.com/2017/08/thecrypto-currency-debate-future-of.html? $\mathrm{m}=1$; Spencer Bogart, Examining Bitcoin's Valued Attributes: A Letter to the SEC, MEDIUM (June 27, 2019), https://medium.com/blockchain-capital-blog/examiningbitcoins-valued-attributes-a-letter-to-the-sec-4273edcb1 e8a; Larry Cermak, Morgan Stanley Report: The Bitcoin Thesis Is 'Rapidly Morphing', Cryptos Highly Correlated, BLOCK (Nov, 1, 2018), https://www.theblockcrypto.com/post/2578/morgan-stanley-releases-a-report-looking-at-the-currentstate-of-cryptocurrencies ("Morgan Stanley starts off the report by noting that bitcoin's thesis has been 'rapidly morphing'. It details the perceived change in narratives, which started as digital cash, moved to store of value, and is now an institutional investment class.").

${ }^{43}$ See Graham Steele, The Miner of Last Resort: Digital Currency, Shadow Money and the Role of the Central Bank, SSRN ELEC. J. (2020), https://papers.ssrn.com/sol3/papers.cfm?abstract id=3600073.

44 Daniel K. Tarullo, Member, Bd. of Governors of the Fed. Reserve Sys., Remarks to the Federal Reserve Bank of San Francisco Conference on Challenges in Global Finance: Shadow Banking After the Financial Crisis 2 (June 12, 2012), https://www.federalreserve.gov/newsevents/speech/tarullo $20120612 \mathrm{a} . \mathrm{htm}$.

${ }^{45} \mathrm{~A}$ blockchain is, in the simplest of terms, a time-stamped series of immutable records of data that is managed by a cluster of computers not owned by any single entity. Each of these blocks of data (i.e. block) is secured and bound to each other using cryptographic principles (i.e. chain).

${ }_{46}$ GRAEBER, supra note 5, at 39. 
have overcome the geographic limitations that hindered wide adoption of previous forms of non-state money.

Bitcoin may rely on new physical technology, but money, fundamentally, is a social technology that originally allowed privately issued IOUs to circulate as a medium of exchange. Returning to the villager in need of a pig, rather than barter for it, that villager could issue an IOU to the provider of the pig, who is then entitled to claim the IOU at a future date and redeem something of equivalent value to one pig. As Felix Martin notes, "For sellers to accept buyers' IOUs in payment, they must be convinced of two things.",47 First, they "must have reason to believe that the debtor whose obligation they are about to accept will, if it comes to it, be able to satisfy their claim," and second, "sellers must also trust that third parties will be willing to accept the debtor's IOU in payment as well."48

Naturally, these two conditions are easier to meet in close-knit societies where everyone knows one another. But, as Americans in the mid-nineteenth century discovered, token-based money breaks down once you start transacting with parties that hail from outside your immediate geographic area, or if you live in a large enough city where it is simply impossible to know the creditworthiness of every IOU issuer. As David Graeber observes, "Providing a sufficient number of IOUs to allow everyone even in a mediumsized city to be able to carry out a significant portion of their daily transactions in such currency would require millions of tokens." 49 Thus, the key element underpinning token-based monetary systems is trust, specifically, "the measure of one's trust in other human beings."

Cryptocurrency attempts to solve the geographic limitations of previous forms of token-based money by representing a new form of community that is made possible by the internet. As Twitter and Square CEO Jack Dorsey said, "The world ultimately will have a single currency, the internet will have a single currency. I personally believe that it will be bitcoin." 51 If the internet constitutes a new, digital, and borderless state, then it necessarily follows that this state will issue its own currency. The question then becomes, why should netizens trust this currency?

\section{B. CRYPTOCURRENCY AND THE CREDIT THEORY OF MONEY}

Cryptocurrency does not fit neatly within the credit theory of money because there is no underlying debtor. When you spend a bitcoin, whose obligation does this represent? Bitcoins are not issued; they are created using computer code, and they exist as computer code. This computer code is open source and accessible to all; it cannot be changed unless a majority of the computing power on the Bitcoin network agrees to change it. If there is no issuer, then who, or what, are Bitcoin users trusting?

${ }^{47}$ MARTIN, supra note 7 , at 28.

${ }^{48} I d$.

49 GRAEBER, supra note 5, at 47

${ }^{50} \mathrm{Id}$.

${ }^{51}$ Alexandra Frean, Bitcoin Will Become the World's Single Currency, Twitter Chief Says, SUNDAY TIMES (Mar. 21, 2018, 12:01 AM), https://www.thetimes.co.uk/article/bitcoin-will-become-the-worldssingle-currency-tech-chief-says-66sim0p6b. 
Satoshi Nakamoto, the anonymous Bitcoin creator, understood the central role of trust in sustaining private currencies, which is why the words "trust" or "trusted" appear thirteen times in the nine-page whitepaper that announced Bitcoin's creation to the world in 2008. ${ }^{52}$ Satoshi believed that Bitcoin's success was premised on the absence of trust: "We have proposed a system for electronic transactions without relying on trust." ${ }^{\text {"3 }}$ With all due respect to Satoshi, one bitcoin is not worth thirty-six thousand dollars without those who acquire it trusting in something. ${ }^{54}$

Rather than trust a person, in real or legal form, Bitcoin's revelation was its underlying blockchain technology that allows network participants "to trust the information recorded on a shared ledger without trusting anyone to validate it." 55 Some have called this "blockchain trust," 56 while others refer to it as "trustless trust." $" 57$ The end result is that for the first time, a system exists that allows users to confidently transmit value without having to trust any other users of the system or any kind of central administrator. ${ }^{58}$ The outcome is an asset that many of its proponents refer to as "digital gold," due to it being portable, liquid, pseudonymous, and scarce. ${ }^{59}$ But this comparison ignores the historical reality that even gold coins were IOU money, owing to the fact that when gold coins were in use "they almost never circulated at their bullion value, ${ }^{\prime 60}$ implying that just like any other currency unit, gold was accepted as payment, because the recipient assumed others would accept the coins as payment. ${ }^{61}$

Despite this new form of trust, Bitcoin and other cryptocurrencies have yet to meaningfully challenge fiat currency in fulfilling the three functions of money. This is partially due to design reasons and partially due to the continued hold of the nation-state as principal architect of social trust. Bitcoin's software limits the total amount of coins that will ever be circulated to twenty-one million, making its supply almost perfectly inelastic. History has shown that for all currencies, state or private, inelastic supply leads to price volatility. Thus, for now, most cryptocurrencies are far too volatile to be used in day-to-day transactions. Furthermore, the process that most decentralized cryptocurrencies use to achieve consensus-where every node verifies and maintains an identical copy of the ledger-is slow and inefficient when compared to traditional intermediated payment systems. But perhaps the biggest impediment to mass adoption of cryptocurrency is the conceptual

${ }^{52}$ See Satoshi Nakamoto, Bitcoin: A Peer-to-Peer Electronic Cash System, BitcolN (Oct. 31, 2008), https://bitcoin.org/bitcoin.pdf.

${ }_{54}^{53} \mathrm{Id}$. at 8 . https://web_archive.org/web/20201010180648if_/https:/www.coindesk.com/price/bitcoin (last visited Oct. 10,2020 ).

55 KeVIN Werbach, THE BlockChaIN AND the New ARChiteCture of TRUST 3 (2018).

56 ld. at 30.

${ }^{57}$ Reid Hoffman, The Future of the Bitcoin Ecosystem and "Trustless Trust" - Why I Invested in Blockstream, LINKEDIN (Nov. 17, 2014), https://www.linkedin.com/pulse/20141117154558-1213-thefuture-of-the-bitcoin-ecosystem-and-trustless-trust-why-i-invested-in-blockstream/.

${ }_{58}$ And in fact, the Bitcoin ledger has yet to have been altered or tampered with.

59 NIALL FERGUSON, THE ASCENT OF MONEY (2008); see Mary Lou Teel, Bitcoin Billionaires Tyler and Cameron Winklevoss, CBS NEws (June 16, 2019, 10:03 AM), https://www.cbsnews.com/news/ bitcoin-billionaires-cameron-and-tyler-winklevoss-gemini/.

${ }^{60}$ GRAEBER, supra note 5, at 46.

${ }^{61} \mathrm{It}$ is true that gold and other precious metals had value independent of their use in coinage, which did imbue these coins with collateral value. This is another component in which the comparison of Bitcoin to digital gold breaks down. 
leap it requires of users who have unquestioningly equated currency with sovereignty. After all, as economist Barry Eichengreen points out, why would you trade "a perfectly liquid dollar, supported by the full faith and credit of the U.S. government, for a cryptocurrency with questionable backing that is awkward to use"? ${ }^{62}$

\section{CRYPTOCURRENCY AND LEGAL TENDER}

As the origin of state-based currency demonstrates, the surest way to accelerate greater use of any currency is to grant it legal tender status. ${ }^{63}$ But why would a state relinquish the benefits of its monopoly over legal tender? For this reason, no country, except El Salvador, recognizes Bitcoin or any other cryptocurrency as legal tender, meaning that by law, it cannot be used to settle a public or private debt, or meet a financial obligation, including tax payments, contracts, and legal fines or damages. Still, some jurisdictions have afforded cryptocurrency elements of legal tender status. In 2018, Ohio became the first U.S. state to accept bitcoin for tax payments. ${ }^{64}$ However, the state never took ownership of any bitcoin; instead, it contracted with a payment processor that converted bitcoin to dollars (the project was shortlived and the state accepted fewer than ten tax payments from the payment processor). ${ }^{65}$

On June 9, 2021, El Salvador bucked tradition, and logic, by becoming the first country to adopt Bitcoin as legal tender. ${ }^{66}$ The Country went beyond the typical lawyer's definiton of legal tender as "any item that a debtor can always depend on to discharge his or her debt" 67 and is requring every economic agent "accept Bitcoin as payment when offered to him by whoever acquires a good or service." 68 Economist George Selgin refers to this provision as "compulsroy tender" and notes: "Very few countries have such Draconian legal tender laws, which in the past were a last-resort of desperate

62 Barry Eichengreen, The Stable-Coin Myth, ProjeCT SYNDICATE (Sept. 11, 2018), https://www.project-syndicate.org/commentary/stable-coins-unviable-cryptocurrencies-by-barryeichengreen-2018-09.

63 Legal tender is anything recognized by law as a means to settle a public or private debt or meet a financial obligation, including tax payments, contracts, and legal fines or damages.

64 Note that municipalities in other countries have since started to accept cryptocurrency for tax payments, although as far as this author can tell, these municipalities are partnering with a payments processor to convert sent cryptocurrency into fiat currency. Canadian Press, Ontario Town Will Soon Accept Bitcoin for Property Tax, CBC CANADA (Mar. 28, 2019, 5:39 PM), https://www.cbc.ca/ news/canada/toronto/innisfil-property-tax-uber-ontario-bitcoin-crypto-1.5075961; see also Natalie Nanowski, You'll Soon be Able to Pay Your Property Taxes with Bitcoin in Richmond Hill, CBC CANADA (July 23, 2019, 5:00 AM), https://www.cbc.ca/news/canada/toronto/bitcoin-richmond-hill-property-taxcoinberry-1.5220107; Paul Vigna, Pay Taxes with Bitcoin? Ohio Says Sure, WaLl ST. J. (Nov. 26, 2018, 9:41 AM), https://www.wsj.com/articles/pay-taxes-with-bitcoin-ohio-says-sure-1543161720.

${ }^{65}$ Andrew J. Tobias, Ohio Suspends Bitcoin Tax-Payment Program. And It's Not Clear If It's Coming Back, Cleveland (Oct. 2, 2019), https://www.cleveland.com/open/2019/10/ohio-suspends-bitcoin-taxpayment-program.html.

${ }^{66}$ Arjun Kharpal, El Salvador Becomes First Country to Adopt Bitcoin as Legal Tender after Passing Law, CNBC (June 9, 2021, 4:48 PM), https://www.cnbc.com/2021/06/09/el-salvador-proposes-law-tomake-bitcoin-legal-tender.html?mc_cid=db97e05980\&mc_eid=87c093d7c5.

${ }^{67}$ John P. Koning, El Salvador Adopts Bitcoin: Hype or History in the Making?, CoINDESK (June 8, $2021,2: 40$ PM), https://www.coindesk.com/el-salvador-bitcoin-legal-tender-koning.

68 Nayib Bukele (@nayibbukele), TwITTER (June 8, 2021, 10:06 PM), https://twitter.com/ nayibbukele/status/1402446890466217985 
governments." 69 Despite the precedent-setting nature of El Salvador's Bitcoin embrace, they are not forfeiting their monetary sovereignty; that already happened in 2001 when the Country adopted the US dollar as its legal tender. ${ }^{70}$ The dollar will remain legal tender alongside Bitcoin and the government has committed to providing Salvadorans instant convertibility from Bitcoin to US dollars. To accomplish this, the Bitcoin law establishes a \$150-million trust at El Salvador's Bandesal development bank, leading some to argue that the trust is simply a vehicle to enrich El Salvador's president and his allies. ${ }^{71}$

In several Asian countries, where cryptocurrency usage is more widespread, laws have been passed that facilitate greater use of cryptocurrency, but they stop well short of granting it legal tender status. ${ }^{72}$ Rather, these laws tend to clarify the legal status of cryptocurrency exchanges and trading. For instance, Japan amended its Payment Services Act to clarify that certain crypto-assets qualify as property that can be used to purchase goods or services. ${ }^{73}$

Other countries, including the two most populous, have reacted to the emergence of cryptocurrency in accordance with historical precedent. In 2017, India's finance minister, Arun Jaitley, remarked, "The government's position is clear, we don't recognize this as legal currency as of now."74 India's central bank went on to ban entities it regulates from dealing with, or providing services to, any individual or business entity "dealing with or settling" cryptocurrencies; the ban was eventually overturned by the country's supreme court, but in March 2021, a senior government official indicated a new law banning cryptocurrencies was in the works. ${ }^{75}$ China has also taken an aggressive stance on cryptocurrency. In 2017 , the Chinese government issued a notice that effectively banned cryptocurrency exchanges and trading platforms; in 2018, the central government issued notices to local governments instructing them to shut down Bitcoin mining operators in their regions; and in May 2021, Chinese financial regulators

${ }^{69}$ Gareth Jenkinson, Adopting the Bitcoin Standard? El Salvador Writes Itself into History Books, COINTELEGRAPH (June 12, 2021), https://cointelegraph.com/news/adopting-the-bitcoin-standard-elsalvador-writes-itself-into-history-books.

${ }_{70}$ The IMF estimates that dollarization reduced interest rates by $4-5 \%$ giving a net saving of around $0.5 \%$ of GDP per annum for the private sector. Andrew Swiston, Official Dollarization as a Monetary Regime: Its Effects on El Salvador (IMF Working Paper WP/I1/129, 2011), https://www.imf.org/ external/pubs/ft/wp/2011/wp11129.pdf.

${ }^{71}$ David Gerard, El Salvador Passes Its Bitcoin Law-and It's a Tether Scam, DAVID GERARD (June 11, 2011), https://davidgerard.co.uk/blockchain/2021/06/11/el-salvador-passes-its-bitcoin-law-and-its-atether-scam/.

${ }_{72}$ See, e.g., Danny Crichton, South Korea Passes One of the World's First Comprehensive Cryptocurrency Laws, TECHCRUNCH (Mar. 5, 2020, 8:07 AM), https://techcrunch.com/2020/03/05/southkorea-passes-one-of-the-worlds-first-comprehensive-cryptocurrency-laws/; Kevin Helms, Regulatory Roundup: 10 Countries Actively Regulating Cryptocurrency Despite Global Crisis, BITCOIN (Apr. 6, 2020), https://news.bitcoin.com/cryptocurrency-global-crisis/.

73 So Saito \& Joerg Schmidt, Digital Assets in Japan, So \& SATo (Apr. 8, 2020), https://innovationlaw.jp/en/digital-assets-in-japan/.

${ }_{74}$ Sujha Sundararajan, Bitcoin Not Legal Tender in India, Finance Minister Says, CoINDESK (Dec. 1, 2017, 5:07 AM), https://www.coindesk.com/bitcoin-not-legal-tender-in-india-finance-minister-says.

${ }_{75}$ Press Release, Rsrv. Bank of India, Statement on Developmental and Regulatory Policies (Apr. 5, 2018), https://www.rbi.org.in/Scripts/BS PressReleaseDisplay.aspx?prid=43574; Aftab Ahmed \& Nupur Anand, India to Propose Cryptocurrency Ban, Penalising Miners, Traders-Source, REUTERS (Mar. 14, 2021, 7:39 PM), https://www.reuters.com/article/us-india-cryptocurrency-ban/india-to-proposecryptocurrency-ban-penalising-miners-traders-source-idUSKBN2B60R0. 
banned financial institutions and payment companies from providing services related to cryptocurrency transactions. ${ }^{76}$

Despite these actions, neither China, India, nor most other countries, prohibit citizens from owning cryptocurrency. ${ }^{77}$ This is a sensible stance given cryptocurrency's limited uptake thus far. For this reason, regulatory agencies in the United States have interpreted cryptocurrency through their own narrow statutory mandates, as opposed to dismissing it as a non-national currency. The Commodity Futures Trading Commission ("CFTC"), Securities and Exchange Commission ("SEC"), Financial Crimes Enforcement Network ("FinCEN"), and the Internal Revenue Service ("IRS") all lay claim to some aspect of cryptocurrency depending on its use. ${ }^{78}$ While a detailed treatment of cryptocurrency regulation in the United States is beyond the scope of this Article, agency interpretations are largely premised on the historical reality that currency is the domain of the sovereign. When the CFTC classified Bitcoin as a commodity in 2015 in an order against Coinflip Incorporated, it stated, "Bitcoin and other virtual currencies are distinct from 'real' currencies, which are the coin and paper money of the United States or another country that are designated as legal tender, circulate, and are customarily used and accepted as a medium of exchange in the country of issuance." $" 79$ Likewise, in its 2013 guidance on "the applicability of the regulations implementing the Bank Secrecy Act ("BSA") to persons creating, obtaining, distributing, exchanging, accepting, or transmitting virtual currencies," FinCEN notes, "In contrast to real currency, 'virtual' currency is a medium of exchange that operates like a currency in some environments, but does not have all the attributes of real currency. In particular, virtual currency does not have legal tender status in any jurisdiction." ${ }^{80}$ However, the risk in basing regulations on the premise that no jurisdiction recognizes cryptocurrency as legal tender is that these same regulations may be undermined if more countries adopt cryptocurrency

${ }^{76}$ Shen Wenhao, Regulation of Cryptocurrency in China, MONDAQ (June 12, 2020), https://www.mondaq.com/china/fin-tech/944330/regulation-of-cryptocurrency-in-china; Samuel Shen \& Twinnie Siu, China Bans Financial, Payment Institutions from Cryptocurrency Busines, REUTERS (May $18,2021,8: 27$ AM), https:/www.reuters.com/technology/chinese-financial-payment-bodies-barredcryptocurrency-business-2021-05-18\%.

${ }_{77}$ Exact information is difficult to find, but according to the website CryptoNews, as of March 2019, the following countries have completely banned the use of cryptocurrency: Afghanistan, Pakistan, Algeria, Bolivia, Bangladesh, the Republic of Macedonia, Saudi Arabia, Qatar, Vanuatu, and Vietnam. See Countries Where Bitcoin Is Banned or Legal In 2020, CRYPTONEWS, https://cryptonews.com/ guides/countries-in-which-bitcoin-is-banned-or-legal.htm (last visited Jan. 26, 2021). On April 16, 2021, Turkey's central bank banned the use of cryptocurrencies and crypto assets for purchases. See Ece Toksabay, Bitcoin Tumbles after Turkey Bans Crypto Payments Citing Risks, REUTERS (Apr. 16, 2021, 2:13 AM), https://www.reuters.com/technology/turkey-bans-use-cryptocurrencies-payments-sendsbitcoin-down-2021-04-16/.

${ }_{78}$ The act of transferring money or value from one person to another also brings into play U.S. state statutes licensing money transmitters. Most states have clarified that the use of cryptocurrency to transfer funds from one person to another is within their statutes.

${ }^{79}$ Order Instituting Proceedings Pursuant to Sections 6(C) and 6(D) of the Commodity Exchange Act, Making Findings and Imposing Remedial Sanctions, CFTC No. 15-29 at 2 n.2 (Sept. 17, 2015), www.cftc.gov/sites/default/files/idc/groups/public/@lrenforcementactions/documents/legalpleading/enf coinfliprorder09172015.pdf.

${ }_{80}$ Dep't of Treasury, Fin. Crimes Enf't Network, FIN-2013-G001, Guidance on Application of FinCEN's Regulations to Persons Administering, Exchanging, or Using Virtual Currencies (Mar. 18, 2013), https://www.fincen.gov/sites/default/files/shared/FIN-2013-G001.pdf. 
as legal tender. ${ }^{81}$ Immediately after El Salvador announced plans to make Bitcoin legal tender, commenters began to speculate about the legal implications in the US, with some arguing that Bitcoin will no longer be subject to US capital gains tax. ${ }^{82}$ Thus far, no US regulatory agency has adjusted their legal interpretation of cryptocurrency based upon El Salvador's decision, but this may change if more countries follow suit. ${ }^{83}$ Shortly after El Salvador's announcement, politicians in "Argentina, Paraguay, Brazil and Panama took to social media to endorse the decision." 84

\section{LIBRA CHALlENGES StATE-BASED CURRENCIES}

The fragmented nature of cryptocurrency regulation was thrust into public view when Facebook announced its plans for Libra in June 2019. The backlash from the public sector was swift. Within weeks, the leaders of the Financial Stability Board, U.S. Federal Reserve, Bank of England, Bundesbank, and the Bank of France issued statements that their respective institutions would carefully examine Libra and apply tough regulatory standards to it. 85 Furthermore, the Group of Seven ("G7") nations immediately set up a high-level forum, led by the European Central Bank, to examine the risks of digital currencies to the financial system. ${ }^{86}$ Democratic members of the U.S. House of Representatives' ("the House") Committee on Financial Services requested that "Facebook and its partners immediately agree to a moratorium on any movement forward on Libra[,]"87 and a bill was introduced in the House titled "Keep Big Tech Out of Finance Act." 88

Over ten years had passed between Satoshi's whitepaper and the announcement of Libra. In the intervening period, most lawmakers gave little thought to cryptocurrency, and regulatory agencies believed their existing

\footnotetext{
${ }^{81}$ See, e.g., Gary E. Kalbaugh. Virtual Currency, Not a Currency?, 16 J. INT'L Bus. \& L. 26, 31 (2016) ("However, grounding its view in the fact that no virtual currency has 'legal tender status in any jurisdiction' results in regulatory volatility since, by the mere act of designating a virtual currency as legal tender, any sovereign can undermine the CFTC's (and the Financial Crimes Enforcement Network's and the Internal Revenue Service's) primary argument for a virtual currency, such as Bitcoin, being deemed to be a commodity and not a currency.").

${ }_{82}$ Marcelo Prates, Bitcoin in El Salvador, LINKEDIN (June 8, 2021), https://www.linkedin.com/pulse/ bitcoin-el-salvador-marcelo-prates/.

${ }^{83}$ It is unlikely that US regulators will respond to El Salvador's decision because the US dollar remains legal tender and the government of El Salvador will convert citizens' Bitcoin into US dollars.

${ }^{84}$ David Walsh, Bitcoin: Which Countries Could Follow El Salvador in Making Cryptocurrency Legal Tender?, EURONEWS (June 12, 2021), https://www.euronews.com/next/2021/06/12/bitcoin-is-elsalvador-the-first-domino-to-fall-as-latin-america-embraces-cryptocurrencies.

${ }^{85}$ See Kiran Stacey \& Caroline Binham, Global Regulators Deal Blow to Facebook's Libra Currency Plan, FIN. TIMES (June 25, 2019), https://www.ft.com/content/0c1 f3832-96b 1-1 le9-9573-ee5cbb98ed36; see also JD Alois, Federal Reserve Chairman Jerome Powell Comments on Libra Crypto at FOMC Press Briefing, CROWDFUND INSIDER (June 19, 2019, 4:34 PM), https:/www.crowdfundinsider.com/ 2019/06/148598-federal-reserve-chairman-jerome-powell-comments-on-libra-crypto-at-fomc-pressbriefing/; Bundesbank Warns Against Libra, FoREX REV. (July 22, 2019), https://theforexreview.com/ 2019/07/22/bundesbank-wams-against-libra/; Caroline Binham, Chris Giles \& David Keohane, Facebook's Libra Currency Draws Instant Response from Regulators, FIN. TTMES (June 19, 2019), https://www.ft.com/content/5535fb3a-91 ea-11e9-b7ea-60e35ef678d2.

${ }_{86}$ Caroline Binham et al., Facebook's Libra Currency Draws Instant Response From Regulators, FIN. TIMES (June 19, 2019), https://www.ft.com/content/5535fb3a-91 ea-11e9-b7ea-60e35ef678d2.

${ }^{87}$ Press Release, U.S. House Comm. on Fin. Servs., Committee Democrats Call on Facebook to Halt Cryptocurrency Plans (July 2, 2019), https://financialservices.house.gov/news/documentsingle.aspx? DocumentID $=404009$.

${ }_{88}$ See generally Keep Big Tech Out of Finance Act, H.R. 4813, 116th Cong. (2019), https://www.congress.gov/bill/116th-congress/house-bill/4813/text.
} 
tools were sufficient to manage the risks associated with cryptocurrency's use. Why then did Libra spark such virulent reactions?

The simple answer is Facebook. The company was already under scrutiny for potential antitrust violations and its role in election interference. There were also valid concerns around how the company would utilize Libra transaction data given its previous violations of user data and privacy. ${ }^{89}$ However, most of these worries can be subsumed under the primary concern of scale.

Facebook has over 2.3 billion active users globally. This reach made Libra the first real threat to sovereign currencies. Facebook's stated goal was to integrate Libra and its digital wallet subsidiary, Calibra, with its WhatsApp and Messenger services so that users can "send money as easily as sending a message." 90 No one doubted Facebook had the technological capacity to make this happen, and by relying on a stablecoin structure, Libra was designed to eliminate the volatility that has prevented the broader adoption of Bitcoin and similar cryptocurrencies. Stablecoins are cryptocurrencies that maintain a stable value against a target price. ${ }^{91}$ In Libra's case, it was to be fully backed by a basket of bank deposits and short-term government securities. ${ }^{92}$

Basing the reserve on a basket of national currencies supported Facebook's ambition for Libra to be a global currency. As Libra's governing body, the Libra Association, noted, "[F]rom the point of view of any specific currency, there will be fluctuations in the value of Libra."93 However,

${ }^{89}$ In 2011, Facebook settled charges with the Federal Trade Commission ("FTC") that it "deceived consumers by telling them they could keep their information on Facebook private, and then repeatedly allowing it to be shared and made public." And in 2017 the European Commission fined Facebook $€ 110$ million for lying to the Commission by stating it was not possible to automatically match Facebook and WhatsApp users' identities. See Press Release, Fed. Trade Comm'n, Facebook Settles FTC Charges That it Deceived Consumers by Failing to Keep Privacy Promises (Nov. 29, 2011), https://www.fte.gov/newsevents/press-releases/2011/11/facebook-settles-ftc-charges-it-deceived-consumers-failing-keep; see also

Press Release, Eur. Comm'n, Mergers: Commission Fines Facebook $€ 110$ Million for Providing Misleading Information About WhatsApp Takeover (May 18, 2017), https://ec.europa.eu/commission/ presscomer/detail/en/IP_17_1369.

${ }^{90}$ Facebook has renamed its proposed digital wallet to Novi. See Novl, https://www.novi.com/ (last visited June 21, 2020) (information from sections titled "Novi from Facebook" and "How It Works").

91 For a complete explanation of stablecoins, see Nathan Sexer, State of Stablecoins, 2018, CONSENSYS MEDIA (July 24, 2018), https://media.consensys.net/the-state-of-stablecoins-2018$79 \mathrm{ccb} 9988 \mathrm{e} 63$.

92 The initial proposed composition and management of Libra's reserve generated many questions and led to significant debate regarding how Libra should be regulated. In some respects,

Libra resemble[d] a currency board, whereby the management of the exchange rate and money supply are given to a monetary authority that makes decisions about the valuation of a nation's currency, specifically whether to peg the exchange rate of the local currency to a foreign currency, an equal amount of which is held in reserves.

Lee Reiners, What Congress Should Ask About Facebook's New Cryptocurrency, FINREG BLOG (July 2, 2019), https://sites.law.duke.edu/thefinregblog/2019/07/02/what-congress-should-ask-about-facebook s-new-cryptocurrency/. However, in Libra's case, there was to be no monetary policy because "Libra [could] only be created by growing the reserve." Id. Some argued that Libra resembled a money-market mutual fund because the reserve was invested only in short-term government bonds and cash equivalents. However, unlike Libra, money-market funds sell shares directly to the public, which is why others compared Libra to an Exchange Traded Fund. See id; see also Examining Facebook's Proposed Cryptocurrency and Its Impact on Consumers, Investors, and the American Financial System: Hearing on H.R. (Keep Big Tech Out of Finance Act) Before H. Comm. on Fin. Servs., 116th Cong. 15-16 (2018) (statement of Chris Brummer, Professor of Law, Georgetown University Law Center).

${ }_{93}$ Reiners, supra note 83 . This quote was contained in a document published in June 2019 by the Libra Association that explained the Libra reserve. However, the Libra Association has since announced 
because the reserve was to be backed by multiple currencies, the overall volatility in Libra would be dampened as the individual volatilities between various currency pairs within the reserve should average out. Had this version of Libra gained widespread adoption, the volatility between Libra and fiat currency would be irrelevant to Libra users. As Bloomberg columnist Matt Levine stated, "If you buy most things online, and if everything online is priced in Libras, then you'll end up living your life denominated in Libras, and only converting your Libras into dollars on your occasional touristic visits to the physical world." 94

Libra's announcement revealed an uncomfortable truth that had been simmering below the surface for some time-America's largest companies have become a new form of sovereign entity "with a reach and economic influence so broad that some of the duties of sovereign nations have fallen under their aegis."95 Professor David Ciepley describes them as "Leviathan[s] on a leash." 96

Given Facebook's scale and global reach, the company has the ability to "upend the business models of companies that depend on it, or completely change the ways its individual users relate to each other-without them even realizing what has happened."97 Even Facebook CEO Mark Zuckerberg acknowledges that "[i]n a lot of ways Facebook is more like a government than a traditional company." 98 The company has even created its own judicial branch, or what Zuckerberg initially likened to a supreme court, "made up of independent folks who don't work for Facebook, who ultimately make the final judgment call on what should be acceptable speech in a community that reflects the social norms and values of people all around the world." $" 99$

Initially, it was unclear how Facebook planned to profit off of Libra, whose circulation in and of itself would not generate revenue for Libra Association members. ${ }^{100}$ Facebook's digital wallet subsidiary, Calibra, would charge fees, but the company did not disclose what those fees would be and who would pay them (the payor or payee). Regardless, these fees were

several changes to Libra's design and have therefore deleted a number of previously published supporting technical papers, including the paper describing Libra's reserve.

${ }_{94}$ Matt Levine, Facebook Will Make the Money Now, Bloomberg (June 18, 2019, 8:59 AM), https://www.bloomberg.com/opinion/articles/2019-06-18/facebook-will-make-the-money-now.

95 Allison D. Garrett, The Corporation as Sovereign, 60 ME. L. REV. 130, 131 (2008), https://digitalcommons.mainelaw.maine.edu/cgi/viewcontent.cgi?article $=1296 \&$ context $=$ mlr.

96 David Ciepley, The Purpose Debate: Social Good Uprooted, DIRS. \& BDS. (2019), https://www.directorsandboards.com/articles/singlepurpose-debate-social-good-uprooted

[https://perma.cc/5H88- XFWV]. Also, as far back as 1932, seminal corporate theorists Adolf Berle and Gardiner Means explained that, as "[p]ublicly traded corporations ... . had become semi-sovereign entities, with power comparable to that of national states"; they are "quasi-public." Id.

${ }^{97}$ Henry Farrell, Margaret Levi \& Tim O'Reilly, Mark Zuckerberg Runs a Nation-State, and He's the King, Vox (Apr. 10, 2018, 7:44 AM), https://www.vox.com/the-big-idea/2018/4/9/17214752/

zuckerberg-facebook-power-regulation-data-privacy-control-political-theory-data-breach-king.
Franklin Foer, Facebook's War on Free Will, GUARDIAN (Sept. 19, 2017), https://www.theguardian.com/technology/2017/sep/19/facebooks-war-on-free-will.

${ }_{99}$ Farrell et al., supra note 88 . The company ultimately chose the name "Oversight Board." See Nick Clegg, Welcoming the Oversight Board, FACEBOOK (May 6, 2020), https://about.fb.com/news/ 2020/05/welcoming-the-oversight-board/.

100 "Provided they retain some of the currency," association members "will benefit from an increase in the currency's value." Reiners, supra note 83. Furthermore, Libra Association members were entitled to a portion of the interest earned on the Libra Reserve. Id. Furthermore, Facebook is but one member of the Libra Association: "Once the Libra network launches, Facebook, and its affiliates, will have the same commitments, privileges, and financial obligations as any other Founding Member. As one member among many, Facebook's role in governance of the Association will be equal to that of its peers." Id. 
unlikely to generate sufficient revenue to justify the regulatory and public scrutiny the project inevitably faced. Facebook's true motivations were revealed when David Marcus, the head of Calibra and co-creator of Libra, testified in front of the Senate Committee on Banking, Housing, and Urban Affairs on July 16 and 17, 2019. When asked by Senator Tina Smith (D-MN) what the "long-term business opportunity for Facebook" was, Marcus responded that the primary opportunity was

[T] he ability for the [ninety] million small businesses and the many users we have on the platform to transact with one another, so as a result, more commerce on the Facebook platform and our family of apps. And if there is more commerce, there will be more advertising revenue for Facebook. ${ }^{101}$

Here, Facebook's self-realization as a new form of sovereign entity was complete. Zuckerberg has repeatedly referred to his platform as the "digital equivalent of a town square," and because the town square is traditionally a place for commerce, it is only logical that it have its own native currency. ${ }^{102}$ Just as the state utilized its status as common creditor (through its power to levy taxes) to create and circulate sovereign money, Facebook would tap into its unique role as a global online community and marketplace to introduce a native, borderless currency. Rather than levy taxes or charge fees payable in Libra, Facebook's plan to circulate Libra was to integrate it into the company's popular messaging platforms Messenger and WhatsApp. ${ }^{103}$ Facebook may not be a common creditor, but it is a common platform.

\section{E. RETHINKING CRYPTOCURRENCY REGULATION}

Libra presented the first credible challenge to sovereign money, but the state retains a firm enough grip to rein in these new Leviathans-for now. In April 2020, after repeated inquiries and criticism from policymakers and regulators, along with the exit of several Libra Association founding

101 Examining Facebook's Proposed Digital Currency and Data Privacy Considerations: Hearing Before the S. Comm. on Banking, Hous., and Urban Affairs, 116th Cong. 24 (2019), https://www.govinfo.gov/content/pkg/CHRG-116shrg37919/pdf/CHRG-116shrg37919.pdf (statement of David Marcus, Co-Creator, Libra) [hereinafter S. Comm. Hearing regarding Facebook].

102 See Nicholas Thompson, Mark Zuckerberg on Facebook's Future and What Scares Him Most, WIRED (Mar. 6, 2019, 9:33 PM), https://www.wired.com/story/mark-zuckerberg-facebook-interviewprivacy-pivot; see also Mark Zuckerberg, A Privacy-Focused Vision for Social Networking, FACEBOOK (Mar. 6, 2019), https://www.facebook.com/notes/mark-zuckerberg/a-privacy-focused-vision-for-socialnetworking/10156700570096634/.

${ }^{103}$ While the original plan was for Libra to be open source, which would allow third-party developers to build their own digital wallets that were interoperable with Calibra and any other Libra wallet, Marcus made clear during his Senate testimony that these other digital wallets would not be integrated into Facebook products. According to Marcus,

If your question is whether we will embed other wallets inside of WhatsApp and Messenger, the answer is no. If you are asking whether other wallets will have full interoperability, meaning that you do not have to use the Calibra wallet inside of Messenger and WhatsApp to be able to send or receive money to people who are using the Calibra wallet inside of Messenger and WhatsApp, the answer is yes.

$S$. Comm. Hearing regarding Facebook, supra note 92, at 17-18.

${ }_{104}$ McKinsey, a consulting firm, estimates that some sixty trillion dollars of economic activity will resolve into platforms by 2025. See Tanguy Catlin et al., Insurance Beyond Digital: The Rise of Ecosystems and Platforms, MCKINSEY (Jan. 10, 2018), https://www.mckinsey.com/industries/financialservices/our-insights/insurance-beyond-digital-the-rise-of-ecosystems-and-platforms. 
members, Facebook announced plans to scale back the Libra project. ${ }^{105}$ The main changes include offering single-currency stablecoins, akin to "digital dollars in a PayPal account," while maintaining a less prominent multicurrency Libra Coin as originally planned. ${ }^{106}$ According to the new Libra whitepaper, this change was made in response to concerns that a multicurrency Libra Coin may "interfere with monetary sovereignty and monetary policy if the network reaches significant scale and a large volume of domestic payments are made" in Libra Coin. ${ }^{107}$ The Libra Association also abandoned plans to utilize a permissionless blockchain, similar to Bitcoin's, due to policymaker concerns that third parties could utilize the Libra blockchain to facilitate money laundering or terrorist financing. ${ }^{108}$ Finally, in late 2020 , the Libra association rebranded itseldf as Diem and announced plans to launch a single, dollar-pegged stablecoin in 2021. ${ }^{109}$

Despite Facebook's retreat, the Libra experience forced a fundamental rethinking of how cryptocurrency is regulated in the United States. Testifying before the Senate Committee on Banking, Housing, and Urban Affairs less than a week before Marcus in July 2019, Federal Reserve Chairman Jerome Powell reflected on the regulatory gaps that Libra exposed:

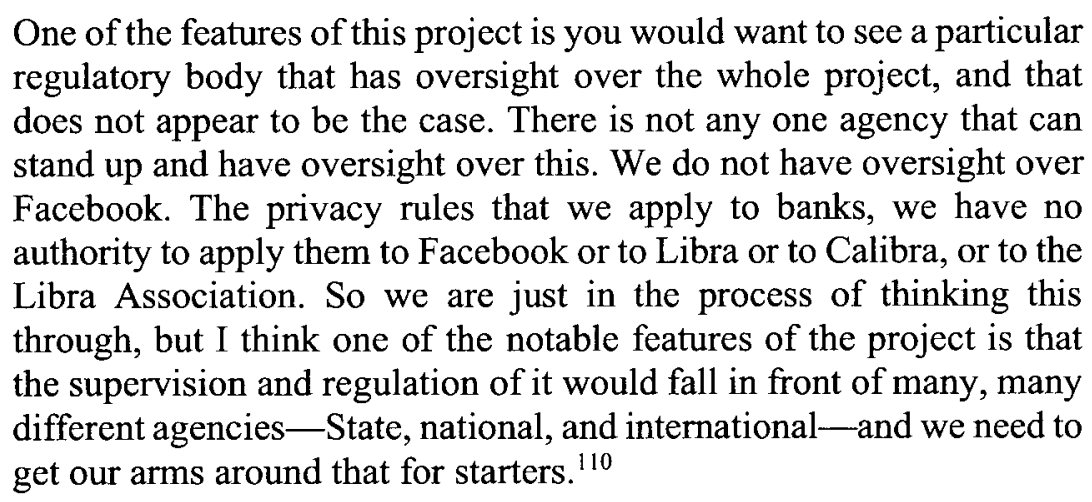

Absent an outright ban on the use of cryptocurrency and its progeny, like stablecoins, regulators are left attempting to understand and control the risks of its use given their relatively narrow legal mandates. This has led to no

${ }^{105}$ In addition, in May 2020, Facebook changed the name of Calibra to Novi. David Marcus, Welcome to Novi, FACEBOOK (May 26, 2020), https://about.fb.com/news/2020/05/welcome-to-novi/.

${ }_{106}$ Nathaniel Popper \& Mike Isaac, Facebook-Backed Libra Cryptocurrency Project is Scaled Back, N.Y. TIMES (Apr. 16, 2020), https://www.nytimes.com/2020/04/16/technology/facebook-libracryptocurrency.html.

${ }_{107}$ Welcome to the Official White Paper, DIEM (Apr. 16, 2020), https://www.diem.com/en-us/whitepaper/.

${ }_{108}$ This change likely benefits Facebook by reducing potential competition from app developers outside the Libra Association.

${ }_{109}$ Nikhilesh De, Libra Rebrands to 'Diem' in Anticipation of 2021 Launch, COINDESK (Dec. 1, 2021, 10:46 AM), https://www.coindesk.com/libra-diem-rebrand. As of June 16, 2021, Diem has yet to launch a single stablecoin. In May 2021, Diem Association announced they were withdrawing their application for a payments license in Switzerland and that they would be partnering with Silvergate, a California state-chartered bank, to issue their stablecoin. See Ryan Browne, Facebook-backed Crypto Project Diem Abandons Swiss License Application, Will Move to the U.S., CNBC (May 13, 2021, 5:56 AM), https://www.cnbc.com/2021/05/12/facebook-backed-diem-is-moving-from-switzerland-to-theus.html.

${ }^{110}$ The Semiannual Monetary Policy Report to the Congress: Hearing Before the S. Comm. on Banking, Housing, \& Urban Affairs, 116 th Cong. 8 (2019) (statement of Jerome H. Powell, Chairman, Board of Governors of the Federal Reserve System). 
shortage of proposals to address the fragmented nature of cryptocurrency regulation, none of which have gained much traction. Former CFTC Chairman Timothy Massad has called on Congress to pass legislation that gives the SEC the authority to "regulate the offering, distribution[,] and trading of crypto-assets, including regulation of trading platforms, custodians (or wallets), brokers[,] and advisors." 111 In March 2020, U.S. Congressman Paul Gosar (R-AZ) introduced the Crypto-Currency Act of 2020 to "clarify which [f] ederal agencies regulate digital assets." 12 The bill divides digital assets into three categories-crypto-commodity, cryptocurrency, and crypto-security - and assigns a primary federal regulator to each. ${ }^{113}$ Other scholars, such as Dan Awrey, have looked more narrowly at stablecoins and noted that they represent a new form of privately-issued monetary liability; but, unlike traditional forms of privately-issued money, like bank deposits, these new private issuers lack the legal certainty and unified regulatory framework that allows users to rest easy knowing that their money is "safe." 114 Awrey proposes a National Money Act that would require the Office of the Comptroller of the Currency ("OCC") to create a "new licensing regime based on three distinct categories of financial institutions." 115 One such category would include firms that issue monetary liabilities but do not "create" money by making loans (that is, fractional reserve banking). ${ }^{116}$ Each category would then be subject to a tailored supervisory regime that reflects "the specific risks posed by their respective business models." 117

These proposals treat cryptocurrency as but the latest in financial sector innovation and place the onus on regulators and their congressional overseers to adjust. The proposals stop well short of considering cryptocurrency to be a legitimate challenge to sovereign currencies and do not grant it legal tender status. But, regulation brings the veneer of legitimacy and an invitation for broader adoption on the part of consumers. Even so, regulatory clarity alone is unlikely to entice enough users to forgo fiat currency in favor of cryptocurrency, thereby undermining state authority.

When it comes to cryptocurrency, the real risk to sovereignty comes from the state itself. Professor J.S. Nelson has called for cryptocurrencies to be "regulated as their own category of non-sovereign fiat currencies." Nelson asserts that rather than rely on the historical notion of currency as the domain of the sovereign, regulators should look to "the qualities of the communities behind" a given cryptocurrency's issuance. ${ }^{119}$ After all, Nelson states, "[S]ome corporations... have more revenue, and arguably

111 Timothy G. MASSAD, IT's Time to STRENGTHEN the RegUlation OF CRYPTO-AsSETS 4 (2019), https://www.brookings.edu/wp-content/uploads/2019/03/Timothy-Massad-lts-Time-to-Strengthen-theRegulation-of-Crypto-Assets-2.pdf.

${ }_{112}$ Crypto-Currency Act of 2020, H.R. 6154, 116 th Cong. (2019).

${ }^{113} I d$. at $\$ \S 2-3$. Respectively, the three categories would be governed by the Commodity Futures Trading Commission ("CFTC"), the Secretary of the Treasury via the Financial Crimes Enforcement Network ("FinCEN"), and the Securities and Exchange Commission ("SEC"). Id at $\$ 3$.

114 Dan Awrey, Bad Money, 106 CORNELL L. REV. (forthcoming) (manuscript at 1), http://dx.doi.org/10.2139/ssm.3532681

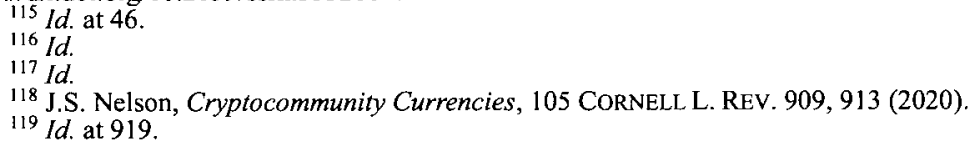


sophistication, than governments." 120 Were Congress to heed Nelson's advice and recognize the existence of non-sovereign fiat currency in law, it would undermine its own authority and hand much of it to the large corporations that would likely stand behind these new currencies.

Regulatory agencies can also undermine the dollar's status, and by extension sovereign authority, by accommodating the use of cryptocurrency in the market sectors they oversee. In July 2020, the OCC published an interpretive letter clarifying that national banks and federal savings associations are authorized to provide cryptocurrency custody services for customers. ${ }^{121}$ In September 2020, the agency released another interpretive letter clarifying national banks' and federal savings associations' authority to hold deposits that serve as reserves for certain stablecoins, ${ }^{122}$ and in January 2021, the agency further opened the door for banks to engage in cryptocurrency activity with the release of yet another interpretive letter that permits national banks and federal savings associations to use independent node verification networks (INVNs) and stablecoins "to perform bankpermissible functions, such as payment activities." 23 "The Acting Comptroller of the Currency at the time the letters were issued, Brian Brooks, previously served as chief legal officer for the digital currency exchange Coinbase immediately prior to joining the OCC. ${ }^{124}$ As Acting Comptroller, Brooks expressed his admiration for decentralized cryptocurrencies, noting in one interview, "I'm a believer in decentralization. At the end of the day, I think that stablecoins and other blockchain-based tokenization of dollars are the most resilient model for long-term faster payments." 125 In another interview, Brooks stated, "Stablecoin is to the dollar what email is to the letter." 126

Brooks' support for stablecoins is premised on a desire to speed up the settlement process for dollar-based transactions. Were this to happen, it "may help preserve the role of the dollar in the financial system," according to Brooks. The problem with this logic is that it evaluates currency through a technological prism as opposed to looking at the qualities of the state standing behind the currency. If superior technology is the goal, then it only makes sense to allow technology companies to issue and circulate currency. After all, few would argue that the government provides technologically superior products compared to the private sector. But as with Libra, even if

$120 \mathrm{Id}$

121 OFFICE OF THE COMPTROLLER OF THE CURRENCY, INTERPRETIVE LETTER NO. 1170, AUTHORITY of a National Bank to Provide CRyptocurRency Custody Services for CuSTOMERS (2020), https://www.occ.gov/topics/charters-and-licensing/interpretations-and-actions/2020/int 11 70.pdf.

122 OFFICE OF THE COMPTROLLER OF THE CURRENCY, INTERPRETIVE LETTER No. 1172, OCC CHIEF COUNSEL'S INTERPRETATION ON NATIONAL BANK AND FEDERAL SAVINGS ASSOCIATION AUTHORITY TO HOLD STABLECOIN RESERVES (2020), https:/www.occ.gov/topics/charters-and-licensing/interpretationsand-actions/2020/int 1172 .pdf.

123 OFFICE OF THE COMPTROLLER OF THE CURRENCY, INTERPRETIVE LETTER No. 1172, OCC CHIEF COUNSEL'S INTERPRETATION ON NATIONAL BANK AND FEDERAL SAVINGS ASSOCIATION AUTHORITY TO USE INDEPENDENT NODE VERIFICATION NETWORKS AND STABLECOINS FOR PAYMENT ACTIVITIES (2021), https:/Www.occ.gov/news-issuances/news-releases/2021/nr-occ-2021-2a.pdf.

124 Note that at the time of writing, Brooks remains the Acting Comptroller.

125 Kollen Post, US Bank Regulator: Dollars on Blockchain 'Better Than Central Bank Monopoly on the Payments System', COINTELEGRAPH (July 29, 2020), https:/cointelegraph.com/news/us-bankregulator-dollars-on-blockchain-better-than-central-bank-monopoly-on-the-payments-system.

126 Ted Knutson, OCC Chief Expects SWIFT-Like Bank-to-Blockchain Connections in 3 to 5 Years, BANKING DIVE (Aug. 14, 2020), https://www.bankingdive.com/news/occ-chief-expects-swift-like-bankto-blockchain-connections-in-3-to-5-years/583521/. 
a stablecoin is backed exclusively by dollars, the linkage becomes irrelevant the more the stablecoin is used. This process is what allowed the United States to gradually decouple the dollar from gold and may allow a future Google-coin or Amazon-coin to ditch the dollar. Were this to happen, the Leviathans would be unleashed, and the outcome would be disastrous for the state and its citizens. As the saying goes, you cannot invite the devil to dinner and get mad when he overstays his welcome. 